\title{
THE INDIAN INSTITUTE OF SCIENCE
}

$\mathrm{T}$

HE Indian Institute of Science owes its existence to the vision of the late Mr. Jamsetti Nusserwanji Tata. In 1889, Mr. Tata, realizing the vital part that science could play in the advancement of human welfare, conceived the idea of founding a research institute which would have as its object the industrial welfare of India. Unfortunately, the founder did not live to see the fruition of his idea and it was left to his two sons, the late Sir Dorab Tata and the late Sir Ratan Tata, to fulfil their father's wishes, with the active support of the late Lord Curzon, then Governor General of India, and Sir K. Seshadri Iyer, who was at that time the Dewan of Mysore. The history of the Institute is presented in the February issue of Science and Culture*; a short account of the Institute on the occasion of the jubilee also appeared in Nature, 183, 644 (1959).

Mr. Tata offered property then worth two hundred thousand pounds (twenty-seven lacs of rupees) as an endowment for launching the Institute. In addition, the Government of Mysore offered 372 acres of land at the north end of Bangalore as a gift so that the Institute would be situated in one of the most favourable locations in India.

The Indian Institute of Science came into formal existence on May 27, 1909, as a postgraduate institution for the promotion of advanced studies and original research. The first batch of students was admitted in July 1911 to the Departments of General and Applied Chemistry and Electrical Technology. The Department of Organic Chemistry was add sd soon after. The Department of Biochemistry was opened in 1921, and the Department of Physics in 1933, when Sir C. V. Raman took charge as the first Indian director of the Institute.

From such modest beginnings it has progressed in a number of directions, and is to-day considered to be the leading centre of research and training in engineering and science in India.

The Institute functions as an autonomous body in accordance with a scheme formulated by the Government of India, under the Charitable Endowments Act. The Quinquennial Reviewing Committee (1955) recommended that, in place of the diplomas which it had so far been conferring, the Institute should confer degrees. The Institute is now deemed a

* Science and Culture, 27, No. 2 (February 1961). university under the University Grants Commission Act of 1956 .

During the Second World War the Institute took up for investigation a large number of schemes of research sponsored by the Council of Scientific and Industrial Research, the Council of Agricultural Research, the Indian Medical Research Council, and the Governments of Madras and Mysore. During that period, the Institute planned and established the Department of Aeronautical Engineering. At the close of the Second World War, a further four-year expansion programme was launched with grants from the central Government. Under the programme, the Departments of Metallurgy (1945) and Chemical Technology and Chemical Engineering (1951) were established and laboratories to carry out work on fermentation technology and pharmacology were set up.

For the training of power engineers, a Power Engineering Department was established in 1947, with separate laboratories for electrical, mechanical, civil and hydraulie engineering. A section on Economics and Industrial Psychology, including industrial relations, and affording facilities for research in these subjects, was also started in the same year.

In 1955, under a scheme for the development of facilities for technical education, additional postgraduate courses in automobile engineering (1956), foundry engineering (1956), soil mechanies and foundation engineering (1957), electronic engineering (1956), ultra-short and mierowave enginearing (1956), line communication engineering, and acoustical engineering were provided. Further facilities for research in technical gas reactions, physical metallurgy, hydraulic machines, internal sombustion engineering, electrical measurements and measuring instruments, transmission, distribution and net-work practices hava been added.

Recently a Department of Applied Mathematics and a section of Industrial Engineering Administration have been established.

The Library of the Institute, with about 63,000 volumes of current scientific and technical journals and books, occupies a high place among scientific libraries in India. The Institute celebrated its golden jubilee, commencing February 2, 1959, to mark the completion of fifty years of notable service to the cause of science and engineering in India.

\section{THE INSTITUTE OF SEAWEED RESEARCH}

THE annual report of the Institute of Seaweed Research, Inveresk, Midlothian, Scotland, outlines the expansion in the seaweed industry both in Britain and overseas*. This is due partly to an increase in the use of the seaweeds themselves and partly to the greatly increased use of seaweed extracts.

Seaweed meal factories at Gairloch, Lochmaddy, Kirkwall and Sanday all increased their produc-

*Institute of Seaweed Research, Inveresk. Annual Report for 1960. Pp. 23, (Inveresk, Midlothian: Institute of Seaweed Research, 1961.) tion during 1960, and the products have found a ready market especially to compounders of animal feeding stuffs.

A retail market for seaweed manure has been developed by eight firms, and a new company has produced a soil conditioner made from seaweed, a liquid seaweed extract and a compost accelerator with a seaweed base. Liquid extracts are being used increasingly in agricultural practice.

Alginates continue to be of primary importance, and the Scottish market is holding its own against overseas competition, particularly from France and 
Nova Scotia. America, Iceland and Norway are all producing alginates commercially and there are new ventures in Holland, Australia and South Africa. Increased attention is being paid to the technology of seaweed products, and their use increases, especially in the food, textile-printing and paper-making trades.

The commercial use of mannitol is extending and it may be that its extraction from brown algae will become necessary, since its availability as a by-product in the manufacture of sorbitol does not meet the demand.
The Institute has continued to support fundamental research in a number of universities, and a summary is given of work on algal chemistry carried out in the University of Edinburgh under Dr. E. Percival and Dr. D. J. Manners, and on microbiology under the direction of Prof. G. E. Fogg at University College, London.

The report concludes with lists of publications during 1960, some of which are linked with the Institute while others concern relevant work of scientific importance or commercial development elsewhere.

\section{PUBLIC HEALTH ENGINEERING}

\begin{abstract}
DOSTGRADUATE courses in public health engineering were first given as a joint venture between the Imperial College of Science and Technology and the London School of Hygiene and Tropical Medicine during 1950. They were inspired by the International Health Division of the Rockefeller Foundation, which, besides giving generous financial aid during the first three years, also awarded many bursaries to enable students to attend the courses.

The courses have now become well established and, during the past eleven years, have been followed by 130 full-time and numerous part-time students from many parts of the world. From the start the aim of the courses has been to give a broad education in public health engineering, and emphasis has been placed on the importance of the public health aspects of the engineer's work.

The engineering studies have been supported by specially arranged courses in basic sciences, especially biology and chemistry, which are essential to the public health engineer but not normally taken by engineers, if at all, beyond the level achieved at school or first year at university. This broad treatment has made it possible to satisfy to a considerable degree the requirements of students from many different countries and of varying interests and experience.
\end{abstract}

It is now felt that some provision for alternative courses would be a great advantage, and it is proposed to provide two types of course from October 1961 . The first is similar to the course which has been given since 1950. It is intended for engineers who will be employed mainly on the design or control of public health engineering works in Government or local authority departments, public works departments, water or sewerage undertakings or consulting engineers' offices. The second will be a new, broader type of course intended for persons with education and experience in engineering who are concerned with the general application of public health engineering mersures rather than with detailed design. Such students will usually find employment in newly developing countries where many of the works with which they deal may be comparatively simple from the engineering point of view. These students require a complete knowledge of public health principles and practice, since their work is closely integrated with the public health services and they may have to initiate now methods of environmental control to meet a variety of health problems. * Imperial College of Seience and Technology; and London School
of Hygiene and Tropical Medicine (University of London). Postgraduate Courses in Public Health Engineering. Pp. 15. (London: graduate Courses in Public Health Engineering. Pp. 15. (London: Hygiene and Tropical Medicine, 1961.)

\section{CHEMOTHERAPY OF MALARIA}

$\mathrm{N}$ a recent issue of the W.H.O. Chronicle*, Dr. L.J. Bruce-Chwatt, head of the Research and Intelligence Section of the World Health Organization's Division of Malaria Eradication, has outlined changes being made in the drugs used in the campaign to eradicate malaria. Dr. Bruce-Chwatt suggests that research on the biochemistry of anti-malarial drugs is badly needed and directs attention to the renewed. interest in drug combinations and associations.

The rationale of the present use of drugs in malaria eradication programmes carried out by the World Health Organization is as follows:

(1) Schizontocidal drugs (ohloroquine or amodia. quine) are used occasionally in the early stage of the attack phase, more generally in the late stage of the attack phase, and always in the consolidation phase for the 'presumptive treatment' given to all suspected cases of malaria for relief of clinical symptoms. The administration of a single dose of the drug to all detected fever cases is one of the characteristics of

*W.H.O. Chronicle, 15, No, 4 (April 1961). the surveillance activity that starts towards the latter part of an attack phase of malaria eradication, covers the whole of the consolidation phase, and extends over at least part of the maintenance phase.

(2) A sporontocidal drug (generally pyrimethamine) is often associated with the schizontocidal drug in the 'presumptive treatment' of the attack and consolidation phases with the purpose of making the suspected case of malaria non-infective to Anopheles vectors.

(3) Mass administration of schizontocidal drugs, alone or in association with such sporontocidal drugs as pyrimethamine or primaquine, has also been adopted during the attack phase together with residual spraying when the conditions are such that anti-anopheline measures are unlikely to have a rapid or complete effect. This use of drugs is still tentative; they have been given either as a single dose at long intervals at the time of residual spraying or as $a$ repeated (weekly or monthly) dose for some definite period. 